\title{
Tumor-infiltrating lymphocytes in colorectal cancers with microsatellite instability are correlated with the number and spectrum of frameshift mutations
}

David Tougeron $^{1,2}$, Emilie Fauquembergue ${ }^{1}$, Alexandre Rouquette ${ }^{3}$, Florence Le Pessot ${ }^{1,3}$, Richard Sesboüé ${ }^{1}$, Michèle Laurent ${ }^{3}$, Pascaline Berthet ${ }^{4}$, Jacques Mauillon ${ }^{5}$, Frédéric Di Fiore ${ }^{1,2}$, Jean-Christophe Sabourin ${ }^{1,3}$, Pierre Michel ${ }^{1,2}$, Mario Tosi ${ }^{1}$, Thierry Frébourg ${ }^{1,5}$ and Jean-Baptiste Latouche ${ }^{1,5}$

${ }^{1}$ Inserm, U614, Faculty of Medicine, Institute for Medical Research, Rouen, Northwest Cancéropôle, France; ${ }^{2}$ Digestive Oncology Unit, Department of Gastroenterology, University Hospital, Rouen, Northwest Cancéropôle, France; ${ }^{3}$ Department of Pathology, University Hospital, Rouen, Northwest Cancéropôle, France; ${ }^{4}$ Department of Genetics, CRLCC François Baclesse, Caen, Northwest Cancéropôle, France and ${ }^{5}$ Department of Genetics, University Hospital, Rouen, Northwest Cancéropôle, France

Colorectal cancers with microsatellite instability are characterized by an important density of tumor-infiltrating lymphocytes and a good prognosis. Microsatellite instability results from the inactivation of the DNA mismatch repair system and induces secondary somatic frameshift mutations within target genes harboring repeat sequences in their coding frame. By disrupting the open reading frame, frameshift mutations can result in the appearance of potentially immunogenic neopeptides. To determine the frameshift mutations inducing a T-cell response during the development of a tumor with microsatellite instability, we studied in 61 colorectal cancer patients with microsatellite instability, using a fluorescent multiplex PCR comparative analysis, the relative frequency of frameshift mutations within 19 target genes and analyzed the correlation of these frameshift mutations with the density of CD3 + tumor-infiltrating lymphocytes. The four most frequently mutated genes were ACVR2 (92\%), TAF1B (84\%), ASTE1/HTO01 $(80 \%)$ and TGFBR2 $(77 \%)$. The vast majority $(95 \%)$ of the tumors exhibited at least three frameshift mutations, and the number of frameshift mutations was associated with tumor progression (TNM stage, wall invasion and tumor diameter). Tumor-infiltrating lymphocyte density was associated with the overall number of frameshift mutations and with the presence of frameshift mutations within two target genes, namely ASTE1/HTO01 and PTEN. These results strongly argue for the clinical relevance of immunotherapy of colorectal cancers with microsatellite instability.

Modern Pathology (2009) 22, 1186-1195; doi:10.1038/modpathol.2009.80; published online 5 June 2009

Keywords: microsatellite instability; replication error phenotype; tumor-infiltrating lymphocytes; hereditary nonpolyposis colorectal cancer; neoantigens

Microsatellite instability or replication error phenotype, which is observed in $\sim 12 \%$ of colorectal cancers, results from the inactivation of the DNA mismatch repair system and represents a form of genetic instability affecting nucleotide repeats. ${ }^{1}$ In colorectal cancers with microsatellite instability, inactivation of the DNA mismatch repair system results either from a somatic biallelic hypermethyla-

Correspondence: Dr JB Latouche, MD, PhD, Inserm, U614, Faculty of Medicine, 22 Boulevard Gambetta, Rouen, Cedex 76183, France.

E-mail: jean-baptiste.latouche@chu-rouen.fr

Received 2 March 2009; revised 22 April 2009; accepted 23 April 2009; published online 5 June 2009 tion of the MLH1 gene, ${ }^{2,3}$ an epigenetic alteration associated with aging, ${ }^{4}$ or from a germline alteration of one gene allele of the DNA mismatch repair system followed by the somatic inactivation of the other. ${ }^{1,5}$ Heterozygous germline mutations of genes of the DNA mismatch repair system are the cause of the Lynch syndrome or hereditary nonpolyposis colorectal cancer, the most common form of inherited colorectal cancers. ${ }^{6}$ Microsatellite instability induces secondary somatic frameshift mutations within target genes harboring repeat sequences in their coding frame, and some of these target genes control cell cycle, apoptosis or DNA repair such as TGFBR2, BAX or $\mathrm{MSH}_{3}{ }^{6-9}$ It is remarkable that microsatellite instability not only inactivates target 
genes but also, by disrupting the open reading frame, can result in the appearance of neopeptides, some of them being potentially immunogenic. This has been shown, in particular, for TGFBR2, which harbors a 10-base pair (bp) polyadenine tract. ${ }^{10}$ Therefore, colorectal cancers with microsatellite instability represent a rare example of human cancers specifically associated with neoantigens.

Interestingly, tumors presenting a microsatellite instability phenotype are histopathologically characterized by an important density of tumorinfiltrating lymphocytes associated with a Crohnlike reaction with lymphoid nodules ${ }^{11-15}$ and have a better prognosis than colorectal cancers without microsatellite instability phenotype. ${ }^{16,17}$ In colorectal cancers, a high level of infiltrating memory $\mathrm{T}$ cells has been inversely correlated with early metastatic invasion and has been found to be an independent prognosis factor of overall survival. ${ }^{18,19}$ Therefore, the better prognosis of microsatelliteunstable colorectal cancers could be, at least in part, explained by the presence of tumor-infiltrating lymphocytes specific of certain tumor peptides resulting from microsatellite instability.

Recently, it was shown that tumor-infiltrating lymphocytes extracted from tumors of patients with colorectal cancers and microsatellite instability were indeed able to specifically recognize HLArestricted frameshift peptides associated with microsatellite instability and to specifically kill in vitro colorectal cancer cell lines with microsatellite instability. ${ }^{20} \mathrm{~A}$ recent finding was the correlation between pronounced lymphocytic infiltration and overexpression of cytotoxic T-cell markers in tumors with microsatellite instability, suggesting that neoantigens in microsatellite-unstable colorectal cancers may elicit a more potent T-cell response than the one found in microsatellite-stable colorectal cancers. ${ }^{21}$ Indeed, although numerous studies have previously reported the mutation rate of specific targets in colorectal cancers with microsatellite instability, in contrast, only in a few reports a systematic simultaneous molecular profiling of the different microsatellite instability targets that have been identified over the last 10 years was performed. ${ }^{22-24}$ Finally, it is crucial to analyze the correlation between the presence of frameshift mutations and the lymphocyte infiltrate within the tumor. To address these points, we performed a quantitative and qualitative survey of 19 target coding regions and a quantitative study of tumor-infiltrating lymphocytes in 61 microsatellite-unstable colorectal cancer patients.

\section{Materials and methods}

\section{Tumor Samples}

Colorectal tissues were collected from 61 colorectal cancer patients with microsatellite instability (26 males and 33 females, two patients having developed two synchronous tumors, mean age: $65.4 \pm 1.2$ years), who underwent surgery at the Rouen University Hospital between January 2003 and October 2007. The majority of the tumors was TNM stage II or III (80\%), in the right colon $(65 \%)$ and well differentiated (54\%). Eight patients had tumoral recurrence after curative surgery after a median follow-up of 15 months. Of all patients, $18(30 \%)$ presented Lynch syndrome, as defined by the presence of the deleterious germline mutation of a gene (13 patients) of the DNA mismatch repair system or the fulfillment of Amsterdam criteria. ${ }^{6}$ Genomic DNA was extracted either from paraffinembedded tissues, using the DNA extraction kits from Takara (Madison, WI, USA) or from Ambion (Huntingdon, Cambridgeshire, UK), according to the manufacturer's instructions, or from frozen samples by proteinase $\mathrm{K}$ digestion and phenol/chloroform extraction followed by ethanol precipitation, or by using the QIAamp DNA Mini Kit (Qiagen, Courtaboeuf, France). For each patient, genomic DNA was extracted from paired tumor and normal colorectal tissues.

\section{Assessment of Microsatellite Instability}

Assessment of microsatellite instability was carried out by a comparative analysis of DNA from tumor and normal colorectal tissues, for each patient using the five consensus mononucleotide repeats (BAT25, BAT26, NR21, NR22 and NR24), as recommended. ${ }^{25,26}$ Microsatellite instability was defined by the presence of instability affecting at least two markers. According to the French regulation, a written consent had systematically been obtained for germline mutation analyses of the DNA mismatch repair system, which have been performed for medical purposes.

\section{Selection of Target Genes}

We reviewed the literature to select genes containing in their coding regions homopolymeric tracts, which have been reported to be altered in colorectal cancers with microsatellite instability. We focused our study on genes that are likely to be involved in malignant transformation and/or of which frameshift mutations have been shown to generate neoantigens. With these criteria, we selected 19 genes (Table 1), involved in signal transduction, apoptosis, DNA repair, transcription regulation or protein modification. In genes such as $A P C$, containing several nucleotide repeats subjected to frameshift mutations in tumors with microsatellite instability, ${ }^{38}$ we analyzed the sequence corresponding to the alteration that has been reported to be the most frequent one. For the PTEN, SEC63 and PRDM2 genes, we analyzed two distinct repeats, which had been shown to be both frequently altered. The 22 homopolymeric tracts that we analyzed in 
this study had a minimal size of six repeats and mostly corresponded to polyadenines (Table 1).

\section{Fluorescent Multiplex PCR Detection of Frameshift Mutations}

Twenty-one short genomic sequences ( $<210 \mathrm{bp})$ encompassing the 22 mononucleotide repeats were simultaneously PCR-amplified within two multiplex PCRs, using dye-labeled primers (primer sequence and PCR conditions are available upon request). Fluorescent PCR products were separated on an ABI Prism 3100 DNA sequencer (Applied Biosystems, Foster City, CA, USA), and the resulting fluorescent profiles were analyzed using the GeneScan 3.7 software (Applied Biosystems). For each patient, the pattern generated from tumor DNA was superimposed to the one generated from paired distant nonmalignant colorectal tissue DNA. In this comparative analysis, frameshift mutations (dele- tion or insertion of one or more base(s)) are easily detected by a shift of the length of the PCR product generated from tumor tissue, in comparison with the one derived from normal tissue, as validated by sequence analysis (Figure 1). It is essential to determine which frameshift mutations are present in the majority of the tumor cells for biological relevance for immunotherapy. In order to estimate the fraction of malignant cells in the tumor samples, we took advantage of the molecular profile obtained in microsatellite instability analysis: among the five markers, we selected the most unstable one and we divided the height of the aberrant peaks (corresponding to the mutant alleles present only in malignant cells) by the height of the normal peaks (corresponding to the wild-type allele present only in nonmalignant cells) plus the height of the aberrant peaks. We carried out the same calculation for each target gene exhibiting an aberrant profile on fluorescent multiplex PCR (height of aberrant peaks divided by the height of normal peaks plus aberrant

Table 1 Frequency of somatic frameshift mutations within target genes in colorectal cancers with microsatellite instability

\begin{tabular}{|c|c|c|c|c|}
\hline \multirow[t]{2}{*}{ Gene $^{\mathrm{a}}$} & \multirow[t]{2}{*}{ Repeat } & \multirow[t]{2}{*}{ Function of the protein } & \multicolumn{2}{|c|}{ Frequency of frameshift mutations } \\
\hline & & & $\begin{array}{c}\text { Percentage } \\
\text { of tumors } \\
\text { with mutations }\end{array}$ & $\begin{array}{l}\text { Percentage of positive } \\
\text { samples with mutations } \\
\text { in all malignant cells }\end{array}$ \\
\hline$A C V R 2^{22}$ & $(\mathrm{~A})_{8}$ & Growth factor receptor, signal transduction & $92(55 / 60)$ & $35(19 / 55)$ \\
\hline$T A F 1 B^{27}$ & $(\mathrm{~A})_{11}$ & TATA box-binding protein-associated, transcription factor & $84(51 / 61)$ & $0(0 / 51)$ \\
\hline$A S T E 1^{27}$ & $(\mathrm{~A})_{11}$ & Unknown function & $80(48 / 60)$ & $33(16 / 48)$ \\
\hline TGFBR2 $2^{7}$ & $(\mathrm{~A})_{10}$ & Inhibitor of cellular growth, signal transduction & $77(46 / 60)$ & $48(22 / 46)$ \\
\hline$C A S P 5^{28}$ & $(\mathrm{~A})_{10}$ & Pro-apoptotic factor & $67(40 / 60)$ & $7(3 / 40)$ \\
\hline$S E C 63^{22}$ & $(\mathrm{~A})_{9}$ and $(\mathrm{A})_{10}$ & ER membrane protein, regulating protein modification & $63(38 / 60)$ & $8(3 / 38)$ \\
\hline $\mathrm{MSH}^{29}$ & $(\mathrm{~A})_{8}$ & DNA mismatch repair & $52(32 / 61)$ & $12(4 / 32)$ \\
\hline$A I M 2^{22}$ & $(\mathrm{~A})_{10}$ & Interferon inducible protein, signal transduction & $52(27 / 52)$ & $22(6 / 27)$ \\
\hline$P T E N^{30}$ & $(\mathrm{~A})_{6}$ exon 8 & Cell cycle protein, Wnt pathway & $42(24 / 57)$ & $0(0 / 24)$ \\
\hline$P R D M 2^{31}$ & $\begin{array}{l}(\mathrm{A})_{8} \\
(\mathrm{~A})_{9}\end{array}$ & Cell cycle and apoptotic protein & $\begin{array}{l}10(6 / 61) \\
32(15 / 48) \\
11(6 / 55)\end{array}$ & $\begin{array}{l}0(0 / 6) \\
2(1 / 48) \\
0(0 / 6)\end{array}$ \\
\hline$M B D 4^{32}$ & $(\mathrm{~A})_{10}$ & DNA glycosylase and methyl CpG binding protein, & $42(21 / 51)$ & $9(2 / 21)$ \\
\hline$O G T^{33}$ & $(\mathrm{~T})_{10}$ & $O$-linked GlcNAc transferase, protein modification & $40(22 / 55)$ & $9(2 / 22)$ \\
\hline$T C F 4^{34}$ & $(\mathrm{~A})_{9}$ & Transcription factor (Wnt pathway) & $38(19 / 50)$ & $5(1 / 19)$ \\
\hline$H N F 1 A^{35}$ & $(\mathrm{C})_{8}$ & Transcription factor 1 (hepatic) & $33(17 / 52)$ & $0(0 / 17)$ \\
\hline$I G F 2 R^{36}$ & $(\mathrm{G})_{8}$ & Growth factor receptor, signal transduction & $28(17 / 60)$ & $0(0 / 17)$ \\
\hline$R A D 50^{37}$ & $(\mathrm{~A})_{9}$ & Response to cellular DNA damage, DNA repair & $25(14 / 56)$ & $0(0 / 14)$ \\
\hline$B A X^{8}$ & $(\mathrm{G})_{8}$ & Pro-apoptotic factor & $22(13 / 59)$ & $15(2 / 13)$ \\
\hline$M S H 6^{29}$ & $(\mathrm{C})_{8}^{8}$ & DNA mismatch repair & $19(11 / 59)$ & $0(0 / 1)$ \\
\hline$A P C^{38}$ & $(\mathrm{~A})_{7}$ & Wnt pathway & $17(9 / 54)$ & $11(1 / 9)$ \\
\hline
\end{tabular}

${ }^{\mathrm{a}}$ References reporting the presence of somatic frameshift mutations within these genes are indicated.

${ }^{b}$ The frequency of somatic mutations was determined only from tumors yielding reproducible results.

Figure 1 Fluorescent multiplex PCR detection of frameshift mutations in colorectal cancers with microsatellite instability. The fluorescent multiplex PCR profile generated from tumor (red) was superimposed on the one obtained from paired normal tissue (blue). Each peak corresponds to a repeat sequence within the coding region of one target gene. For PTEN, two polyA tracts located within exons 7 and 8, and for PRMD2 two polyA tracts within the same exon (PRDM2 (1) and (2)) were analyzed as separate peaks. The Yaxis displays fluorescence intensity and the $X$ axis indicates the amplicon size in bp. Somatic frameshift mutations can be easily detected by a shift of the amplicon size, as indicated by the arrows. (a) Microsatellite-stable tumor without detectable frameshift mutation. (b) Microsatelliteunstable tumor with frameshift mutations within six target genes (TAF1B, ASTE1/HTO01, AIM2, ACVR2, SEC63 and TGFBR2). (c) MSI tumor with frameshift mutations within 12 target genes (TAF1B, MSH3, ASTE1/HT001, AIM2, ACVR2, IGFR2, TGFBR2, OGT, MSH6, MBD4, RAD50 and TCF4). 
Tumor-infiltrating lymphocytes and microsatellite instability

$\mathrm{D}$ Tougeron et al

npg

a

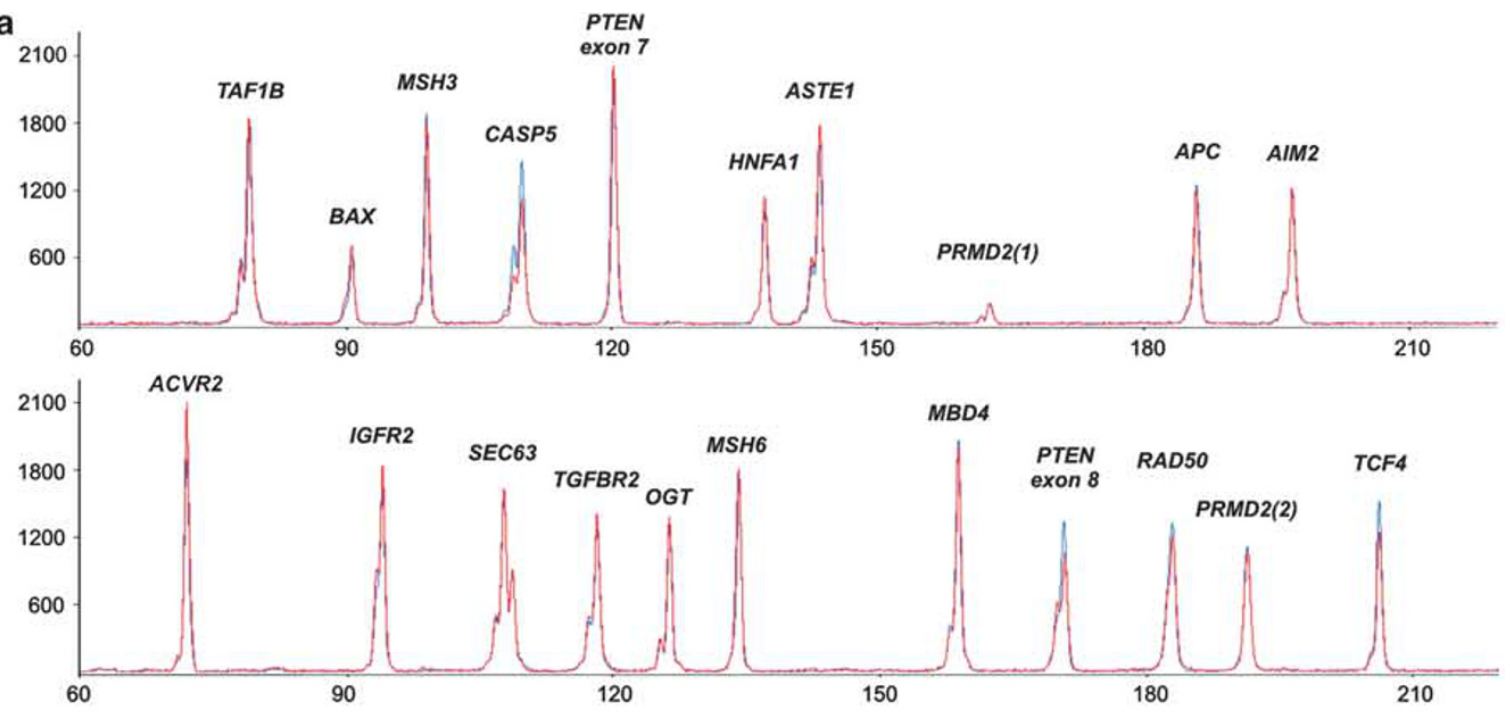

1189

b

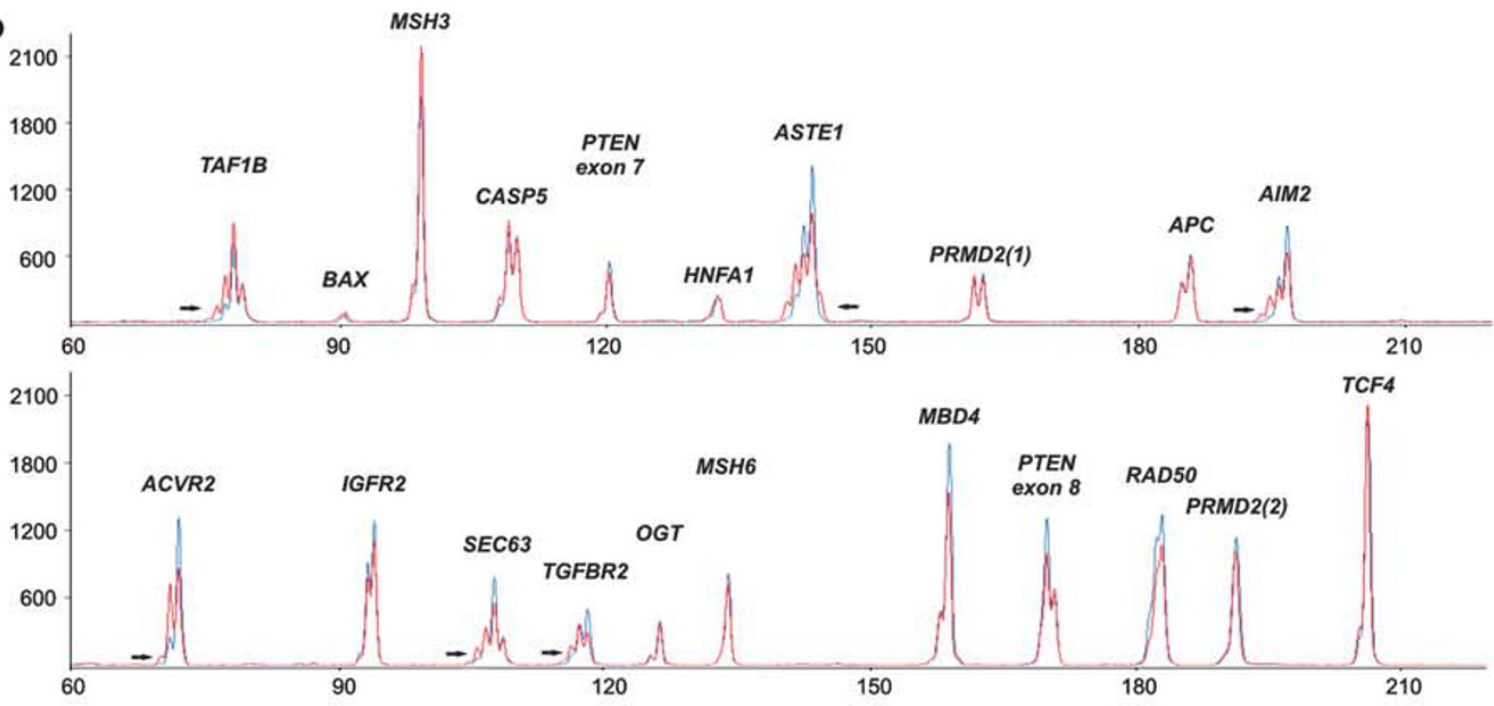

c
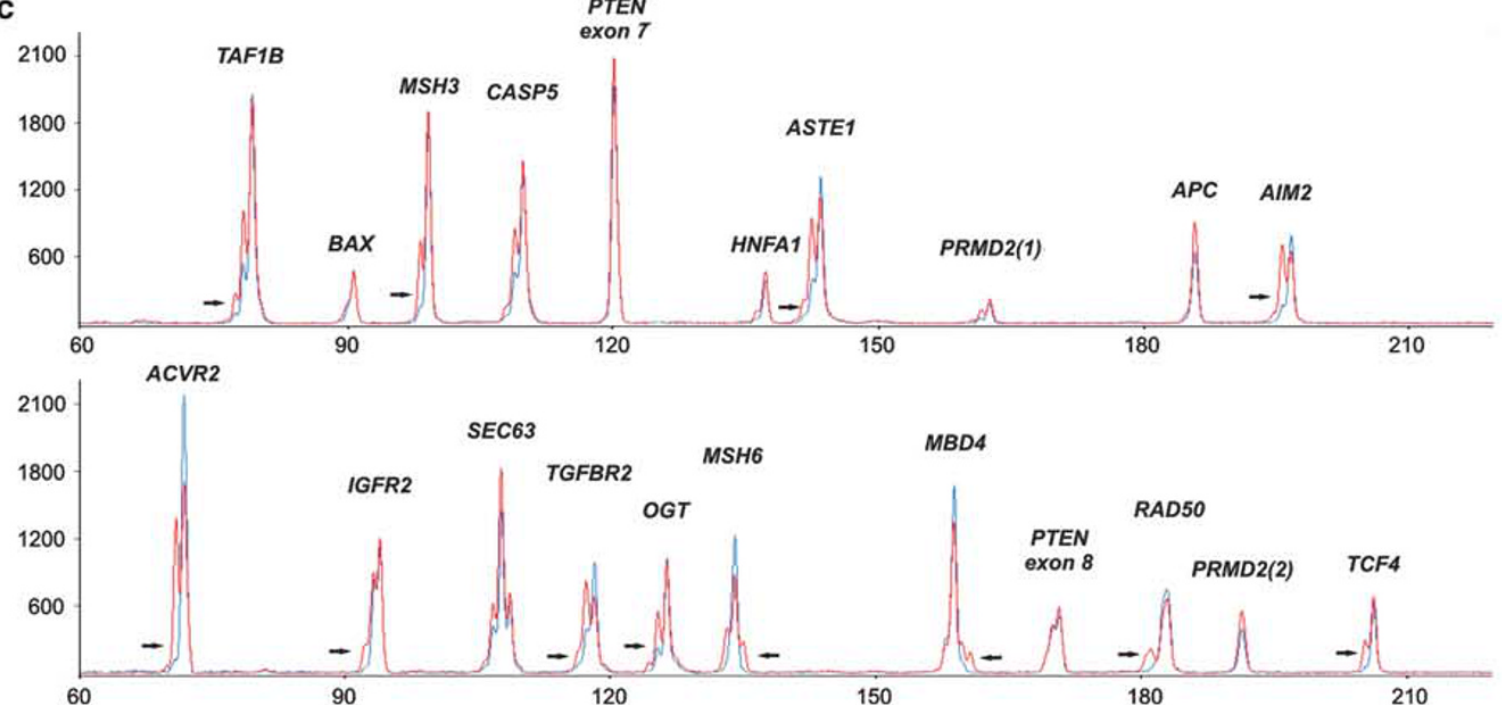

Modern Pathology (2009) 22, 1186-1195 
peaks). If percentages of malignant cells in the samples were similar to the percentages of cells with frameshift mutation in the samples, we concluded that the frameshift mutations were likely to be present in all tumor cells. For each tumor sample, analyses were carried out at least in duplicates, and confirmed, if necessary, by individual fluorescent PCR analysis of the repeats.

\section{Quantification of Infiltrating Lymphocytes}

CD3 immunostaining of $\mathrm{T}$ cells was performed on $4-\mu$ m-thick tissue sections at three sites for each sample (tumor center, invasion front and distant non-malignant site), using the monoclonal antibody F7.2.38 (Dako, Carpinteria, CA, USA) at a dilution of 1:30 and the Ventana BenchMark XT IHC/ISH Staining Module (Ventana Medical Systems, Tucson, AZ, USA), according to the manufacturer's recommended protocol. For each site, six representative digital pictures were taken and scanned to delineate the acellular areas and the stromal and epithelial compartments. Then, the quantification of infiltrating lymphocytes in stromal and epithelial compartments within the non-malignant, tumor center and invasion front sites was determined, after substraction of the acellular areas, using the mean percentage of surface labeled by CD3 immunostaining (MetaMorph software, Molecular Devices, Downingtown, PA, USA). Analysis of the samples from 10 patients led us to estimate that $1 \%$ of tumor-infiltrating lymphocyte staining corresponded to 350 tumor-infiltrating lymphocytes per $\mathrm{mm}^{2}$. Vascular emboli and perinervous invasion were determined by pathologist's examination.

\section{Statistical Analysis}

Statistical analysis for paired comparisons was based on the Wilcoxon test. Associations between different frameshift mutations were analyzed using logistic regression. Only associations with $P<0.0025$ were selected to avoid positive flashes. Other statistical analyses were carried out with a two-sided significance value of 0.05 . All analyses were performed using the Statview software (Statview for Windows, SAS Institute, version 5.0, Cary, NC, USA).

\section{Results}

See Supplementary table for all detailed results.

\section{Frequency of the Frameshift Mutations}

We determined the frequency of frameshift mutations affecting coding repeats within 19 target genes in 61 microsatellite-unstable colorectal cancer patients, by carrying out a comparative fluorescent

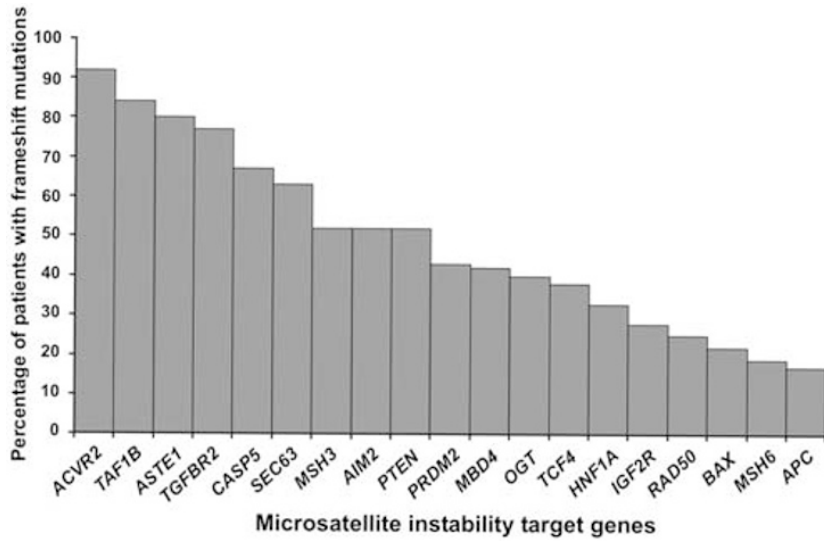

Figure 2 Frequency of somatic frameshift mutations within target genes in colorectal cancers with microsatellite instability. Frequencies of frameshift mutations ranged from 17 to $92 \%$.

multiplex PCR analysis of these repeats between tumor and normal colorectal tissues. Figure 1 shows the multiplex PCR fluorescent profiles of microsatellite-stable colorectal cancers that we used as a negative control and of two representative colorectal cancers with microsatellite instability. The frequency of the different frameshift mutations that we found in this multiplex analysis of 61 colorectal cancer patients with microsatellite instability is shown in Table 1 and Figure 2. Measurement of the shift of the amplicon size, between tumor and paired normal colorectal tissue, showed that the great majority (superior to 95\%) of the frameshift mutations corresponded to one nucleotide deletion within the repeat sequences. The four most frequently mutated genes were ACVR2 (92\%), TAF1B (84\%), ASTE1/HTOO1 (80\%) and TGFBR2 (77\%). In the Lynch subgroup, the frequencies of these frameshift mutations were $89,78,61$ and $72 \%$, respectively. The vast majority $(58 / 61,95 \%)$ of the tumors exhibited at least three frameshift mutations, only one tumor exhibited no detectable frameshift mutation and two tumors had only two frameshift mutations. The mean number of frameshift mutations that we found within the 61 colorectal cancer patients with microsatellite instability was $9 \pm 4$ (6 in the Lynch patients versus 10 in the non-Lynch patients, $P<0.001$ ) and the median number was 8 (Figure 3). We had the opportunity to analyze two patients with two synchronous tumors, and in both cases, the pattern of somatic mutations was different between both tumors. Moreover, the pattern of alterations varied between the tumors from different family members with Lynch syndrome. Interestingly, we found several significant associations between certain frameshift mutations affecting genes often involved in different biological pathways, such as TAF1B and ASTE1/HTO01 $(P<0.001$, $\kappa=0.67), C A S P 5$ and AIM2 $(P=0.002, \kappa=0.46)$ or $R A D 50$ and PRDM2 $(P=0.002, \kappa=0.50)$. 


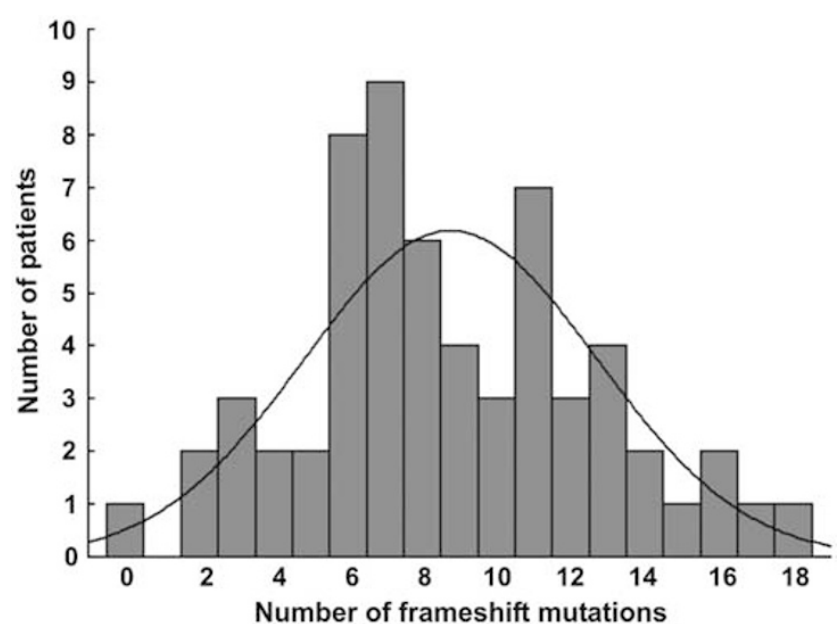

Figure 3 Distribution of frameshift mutation numbers. The mean number of frameshift mutations was $9 \pm 4$ and the median number was 8 .

Determination of the Frameshift Mutations Present in the Majority of the Malignant Cells

By carrying out a comparative analysis between the fluorescent profiles generated for each patient from tumor and normal colorectal tissues used to assess microsatellite instability, we determined the mean percentage of normal cells present within the tumor samples to be $49.5 \pm 20.5 \%$. This allowed us to determine that frameshift mutations of only ACVR2, ASTE1/HTOO1 and TGFBR2 were present in all malignant cells within at least one-third of the tumors. In contrast, we did not find any tumor with microsatellite instability harboring frameshift mutations of TAF1B, PTEN, HNF1A, IGFR2, RAD50 or MSH6 in all malignant cells (Table 1).

\section{Correlation of Frameshift Mutations with Clinical Characteristics}

We found that the number of detected frameshift mutations was associated with age, TNM stage, wall invasion, tumor diameter and the presence of vascular emboli and perinervous invasion (Table 2). Certain frameshift mutations, in genes such as MBD4, HNF1A, BAX and $A P C$, were found only in microsatellite-unstable colorectal cancers of higher stages (TNM stage II or more). Disease recurrence was only associated with the absence of TAF1B frameshift mutation $(P=0.036)$.

\section{Correlation of the Density of Tumor-Infiltrating Lymphocytes with the Presence of Frameshift Mutations}

The mean density of tumor-infiltrating lymphocytes (calculated from the values obtained for each tumor in the tumor centre and invasion front) in 52 analyzed colorectal cancer patients with
Table 2 Factors associated with the number of frameshift mutations

\begin{tabular}{|c|c|c|}
\hline$n=61$ & $\begin{array}{l}\text { Mean number of } \\
\text { frameshift mutations }\end{array}$ & P-value \\
\hline Age (years) & & $<0.001$ \\
\hline$<60$ & 6.4 & \\
\hline$\geq 60$ & 10.2 & \\
\hline TNM stage & & 0.049 \\
\hline I & 5.1 & \\
\hline II & 9.7 & \\
\hline III & 9.1 & \\
\hline IV & 9.5 & \\
\hline Wall invasion & & 0.004 \\
\hline T1 or 2 & 5.1 & \\
\hline T3 or 4 & 9.5 & \\
\hline Node invasion & & NS \\
\hline No & 8.9 & \\
\hline $\mathrm{N}+$ & 9.1 & \\
\hline Mean tumor diameter (cm) & & 0.001 \\
\hline$<6$ & 6.7 & \\
\hline$\geq 6$ & 10.5 & \\
\hline Tumoral differentiation & & NS \\
\hline Well & 8.6 & \\
\hline Moderate & 9.5 & \\
\hline Poor & 11.4 & \\
\hline Vascular emboli & & 0.047 \\
\hline No & 8.1 & \\
\hline Yes & 10.3 & \\
\hline Perinervous invasion & & 0.02 \\
\hline No & 8.1 & \\
\hline Yes & 11.0 & \\
\hline Tumoral recurrence & & NS \\
\hline No & 8.0 & \\
\hline Yes & 8.8 & \\
\hline
\end{tabular}

$n$, the number of patients; NS, not significant.

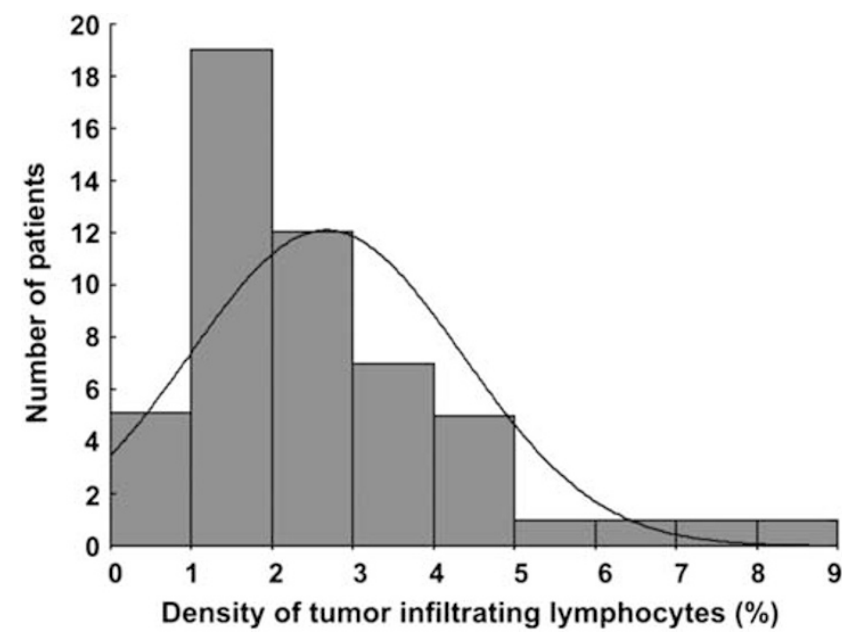

Figure 4 Distribution of tumor-infiltrating lymphocyte density. The mean tumor-infiltrating lymphocyte density in 52 analyzed microsatellite-unstable colorectal cancer samples was $2.76 \pm 1.87 \%$ (range: $0.51-8.7 \%$ ) 

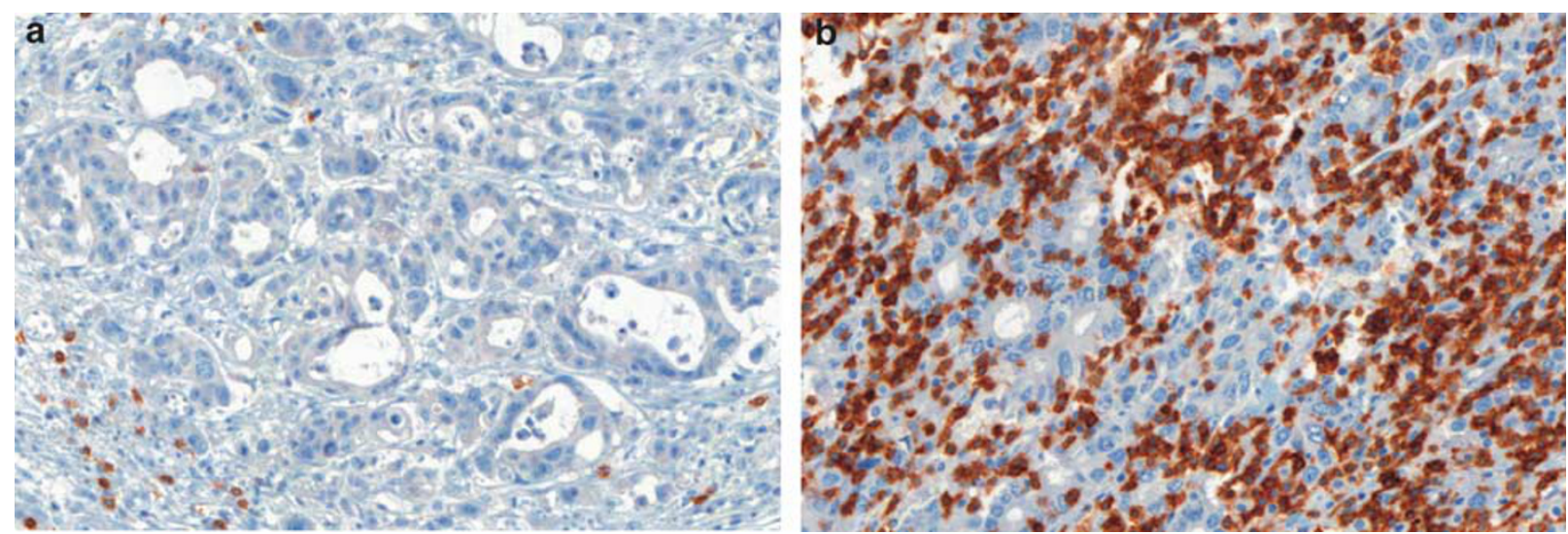

Figure 5 Variability of the tumor-infiltrating lymphocyte density in tumors with microsatellite instability. Tumor-infiltrating lymphocytes were immunostained using an anti-CD3 antibody revealed by peroxidase reaction. (a) Tumor with a low density of tumor-infiltrating lymphocytes. (b) Tumor with a high density of tumor-infiltrating lymphocytes.

Table 3 Correlation between tumor-infiltrating lymphocyte density and the number and type of frameshift mutations

\begin{tabular}{lcc}
\hline & $\begin{array}{c}\text { Tumor infiltrating } \\
\text { lymphocytes } \\
(\% \pm \text { s.d. })\end{array}$ & P-value \\
& & \\
\hline $\begin{array}{l}\text { Median number of frameshift } \\
\text { mutations }\end{array}$ & 0.01 \\
$\quad<8$ & $2.0 \pm 1.0$ & \\
$\quad \geq 8$ & $3.1 \pm 1.9$ & \\
ASTE1 frameshift mutations & & 0.01 \\
$\quad$ No & $1.6 \pm 0.6$ & \\
$\quad$ Yes & $3.1 \pm 2.0$ & \\
$\quad$ PTEN (exon 7) frameshift & & 0.007 \\
mutations & & \\
$\quad$ No & & \\
$\quad$ Yes & $2.5 \pm 1.7$ & \\
\hline
\end{tabular}

s.d.: standard deviation.

microsatellite instability was $2.76 \pm 1.87 \%$ (Figure 4 ). There was an important variability among colorectal cancers with microsatellite instability, as illustrated in Figures 4 and 5 (range: 0.51-8.7\%). This mean density of tumor-infiltrating lymphocytes in tumors was significantly higher than that in the paired distant nonmalignant colorectal sites $(1.83 \pm 1.10 \%$, $P=0.01)$. In tumors, the highest values were observed at the invasion front in the stromal compartment $(3.23 \pm 2.11 \%)$. As indicated in Table 3, we found that the density of tumorinfiltrating lymphocytes in tumors was correlated with the overall number of frameshift mutations $(P=0.01)$, and associated with the presence of frameshift mutations within two targets, namely ASTE1/HTO01 and PTEN (exon 7). The density of tumor-infiltrating lymphocytes was more important if these mutations were present in all tumor cells, without reaching statistical significance. For
CASP5, only when the frameshift mutations were present in all the malignant cells, the percentage of tumor-infiltrating lymphocytes was clearly higher $(5.5 \pm 1.6 \%$ versus $2.2 \pm 1.2 \%, P=0.02)$, although this result was obtained only in $3 / 60$ patients.

\section{Discussion}

The simultaneous analysis of 19 known microsatellite instability target genes in 61 colorectal cancer patients with microsatellite instability, using a fluorescent multiplex PCR comparative analysis, showed that the most frequently mutated genes in colorectal cancers with microsatellite instability are ACVR2, TAF1B, ASTE1/HTO01 and TGFBR2. The frequency of the frameshift mutations that we found for the 19 targets (Table 1) is in agreement with previous studies, except for $A P C$ and $B A X{ }^{8,38}$ The discrepancy that we observed for the latter genes is probably explained by the fact that our analysis was restricted to one repeat per gene, whereas previous reports had carried out a complete analysis of the corresponding targets. Although some of the mutations that we detected might only reflect the intrinsic genetic instability of tumors with microsatellite instability and may therefore be considered as passenger mutations, this study provides the following arguments confirming that some of these frameshift mutations, such as those affecting ACVR2, ASTE1/HTOO1 and TGFBR2, could play a key role in malignant transformation resulting from microsatellite instability: (i) their frequency, (ii) their presence in all malignant cells, suggesting that these alterations occur early and provide a selective advantage for tumor growth and (iii) the significant association of these mutations with other frameshift mutations (such as ASTE1/HTOO1 and TAF1B), which argues that they are not at random. It is interesting that in addition to the 61 colorectal cancer patients of the study, we found a case of 
severe colorectal dysplasia with microsatellite instability, which displayed frameshift mutations within ACVR2, TGFBR2 and ASTE1/HTO01, confirming that these mutations, at least in some cases, occur early during microsatellite instability-induced colorectal carcinogenesis. The most frequently mutated genes were similar in Lynch syndrome or in sporadic colorectal cancers with microsatellite instability, suggesting that the routes to cancer are not different in both groups.

Although our study was restricted to the analysis of 19 target genes and does not provide a global view of the mutation rate in microsatellite unstable tumors, the mean number of frameshift mutations that we found clearly shows that a microsatelliteunstable tumor exhibits numerous frameshift mutations, predicted to inactivate key genes controlling apoptosis, cell cycle and DNA repair. As previously reported for Lynch patients, we observed that the number of somatic mutations was correlated with tumor stage,$^{39}$ not only in Lynch patients but also in all microsatellite-unstable colorectal cancers. If somatic frameshift mutations of certain target genes had previously been shown to be correlated with tumor progression and prognosis of sporadic microsatellite unstable tumors, in contrast, the correlation between the overall number of frameshift mutations and tumor progression had not been previously established. ${ }^{22,40-42}$ In our series, only nine patients experienced disease recurrence; then it was difficult to detect a correlation between frameshift mutations and disease recurrence. The fact that we most often found several frameshift mutations in microsatelliteunstable tumors suggests that accumulation of several mutations may be required for malignant transformation of a microsatellite-unstable cell, as suspected by Tsao et al. ${ }^{43}$ In the context of Lynch syndrome, this probably explains the incomplete penetrance of the MMR gene mutations, which has been estimated to $\sim 70 \%{ }^{44}$

Although it has been suspected that the high density of tumor-infiltrating lymphocytes observed in tumors with microsatellite instability, used as a pathological signature of these tumors, was related to the occurrence of frameshift mutations resulting into neoantigens, no study had previously analyzed, to our knowledge, the correlation between the density of tumor-infiltrating lymphocytes and the presence of characterized frameshift mutations. Our study confirms that the density of tumor-infiltrating lymphocytes is high in tumors with microsatellite instability, especially at the tumor invasion front in the stromal compartment, in agreement with the notion that malignant cells with microsatellite instability are probably immunogenic through the expression and the presentation of neoantigens to $\mathrm{T}$ cells. Recently, it has been shown that CpG island methylator phenotype is also associated with tumorinfiltrating lymphocyte density. ${ }^{45}$ This may be due to a link between $\mathrm{CpG}$ island methylator phenotype and microsatellite instability. Moreover, the density of tumor-infiltrating lymphocytes was significantly associated with the number of frameshift mutations and the presence of frameshift mutations in ASTE1/ HTO01 and PTEN. The development of immunotherapeutic strategies in microsatellite-unstable colorectal cancers requires determining frameshift mutations for which putative nonsense-mediated mRNA decay should be kept in mind. It could hamper the production of mutated proteins and influence their role in tumorigenesis and in antitumor immunity. ${ }^{46}$ Interestingly, frameshift mutations in ASTE1/HTO01, generating a premature stop codon in the last exon, are not predicted to lead to any nonsense-mediated mRNA decay. The mutated ASTE1/HTO01 proteins could therefore be expressed at a high level and be particularly immunogenic. It is also noteworthy that the ASTE1/HTO01 frameshift mutation has been shown to result in the appearance of neoantigens, which could be recognized by specific $\mathrm{T}$ cells, and that tumor-infiltrating lymphocytes isolated from Lynch tumors specifically recognized corresponding frameshift peptides and killed colorectal cancer cells with microsatellite instability in vitro. ${ }^{20}$ Nevertheless, the ultimate proof of the specific immune response against the particular putative neoantigens that we characterized remains to be established.

In conclusion, the most significant result emerging from this study is that, in tumors with microsatellite instability, the overall number of frameshift mutations is associated with tumor progression and tumor-infiltrating lymphocyte density, which argues for the clinical relevance of T-cell immunotherapy strategies in this type of tumors. In this regard, this study provides evidence that ASTE1/HTO01 and PTEN could be especially promising targets for immunotherapy in colorectal cancers with microsatellite instability.

\section{Acknowledgements}

We thank Drs D Caillez, P Chenal, J Germain and JJ Michels who provided tumor samples and clinical information for this study. We are grateful to MG Côme for her advice on the use of the MetaMorph software. This study was supported by grants from the French National Cancer Institute (InCa).

\section{Conflict of interest}

The authors declare no conflict of interest.

\section{References}

1 Aaltonen LA, Salovaara R, Kristo P, et al. Incidence of hereditary nonpolyposis colorectal cancer and the feasibility of molecular screening for the disease. $\mathrm{N}$ Engl J Med 1998;338:1481-1487. 
2 Herman JG, Umar A, Polyak K, et al. Incidence and functional consequences of hMLH1 promoter hypermethylation in colorectal carcinoma. Proc Natl Acad Sci USA 1998;95:6870-6875.

3 Cunningham JM, Kim CY, Christensen ER, et al. The frequency of hereditary defective mismatch repair in a prospective series of unselected colorectal carcinomas. Am J Hum Genet 2001;69:780-790.

4 Nakagawa H, Nuovo GJ, Zervos EE, et al. Age-related hypermethylation of the $5^{\prime}$ region of MLH1 in normal colonic mucosa is associated with microsatelliteunstable colorectal cancer development. Cancer Res 2001;61:6991-6995.

5 Julié C, Trésallet C, Brouquet A, et al. Identification in daily practice of patients with Lynch syndrome (hereditary nonpolyposis colorectal cancer): revised Bethesda guidelines-based approach versus molecular screening. Am J Gastroenterol 2008;103:1-11.

6 Gruber SB. New developments in Lynch syndrome (hereditary nonpolyposis colorectal cancer) and mismatch repair gene testing. Gastroenterology 2006;130:577-587.

7 Markowitz S, Wang J, Myeroff L, et al. Inactivation of the type II TGF-beta receptor in colon cancer cells with microsatellite instability. Science 1995;268:1336-1338.

8 Rampino N, Yamamoto $\mathrm{H}$, Ionov $\mathrm{Y}$, et al. Somatic frameshift mutations in the BAX gene in colon cancers of the microsatellite mutator phenotype. Science 1997;275:967-969.

9 Yin J, Kong D, Wang S, et al. Mutation of hMSH3 and hMSH6 mismatch repair genes in genetically unstable human colorectal and gastric carcinomas. Hum Mutat 1997;10:474-478.

10 Saeterdal I, Gjertsen MK, Straten P, Eriksen JA, Gaudernack G. A TGF betaRII frameshift-mutationderived CTL epitope recognised by HLA-A2-restricted CD8+ T cells. Cancer Immunol Immunother 2001; 50:469-476.

11 Jass JR, Do KA, Simms LA, et al. Morphology of sporadic colorectal cancer with DNA replication errors. Gut 1998;42:673-679.

12 Jass JR. Role of the pathologist in the diagnosis of hereditary non-polyposis colorectal cancer. Dis Markers 2004;20:215-224.

13 Shashidharan M, Smyrk T, Lin KM, et al. Histologic comparison of hereditary nonpolyposis colorectal cancer associated with MSH2 and MLH1 and colorectal cancer from general population. Dis Colon Rectum 1999;42:722-726.

14 Smyrk TC, Watson P, Kaul K, Lynch HT. Tumorinfiltrating lymphocytes are a marker for microsatellite instability in colorectal carcinoma. Cancer 2001;91:2417-2422.

15 Michael-Robinson JM, Biemer-Huttmann A, Purdie $\mathrm{DM}$, et al. Tumour infiltrating lymphocytes and apoptosis are independent features in colorectal cancer stratified according to microsatellite instability status. Gut 2001;48:360-366.

16 Gryfe R, Kim H, Hsieh ET, et al. Tumor microsatellite instability and clinical outcome in young patients with colorectal cancer. N Engl J Med 2000;342: 69-77.

17 Benatti P, Gafà R, Barana D, et al. Microsatellite instability and colorectal cancer prognosis. Clin Cancer Res 2005;11:8332-8340.

18 Galon J, Costes A, Sanchez-Cabo F, et al. Type, density, and location of immune cells within human colorectal tumors predict clinical outcome. Science 2006; 313:1960-1964.

19 Pages F, Berger A, Camus M, et al. Effector memory T cells, early metastasis, and survival in colorectal cancer. N Engl J Med 2005;22:2654-2666.

20 Schwitalle Y, Kloor M, Eiermann S, et al. Immune response against frameshift-induced neopeptides in HNPCC patients and healthy HNPCC mutation carriers. Gastroenterology 2008;134:988-997.

21 Le Gouvello S, Bastuji-Garin S, Aloulou N, et al. High prevalence of Foxp3 and IL17 in MMR-proficient colorectal carcinomas. Gut 2008;57:772-779.

22 Calin GA, Gafa R, Tibiletti MG, et al. Genetic progression in microsatellite instability high (MSI-H) colon cancers correlates with clinico-pathological parameters: a study of the TGRbetaRII, BAX, hMSH3, hMSH6, IGFIIR and BLM genes. Int J Cancer 2000; 89:230-235.

23 Duval A, Rolland C, Compoint A, et al. Evolution of instability at coding and non-coding repeat sequences in human MSI-H colorectal cancers. Hum Mol Genet 2001;10:513-518.

24 Mori Y, Yin J, Rashid A, et al. Instabilotyping: comprehensive identification of frameshift mutations caused by coding region microsatellite instability. Cancer Res 2001;61:6046-6049.

25 Buhard O, Cattaneo F, Wong YF, et al. Multipopulation analysis of polymorphisms in five mononucleotide repeats used to determine the microsatellite instability status of human tumors. J Clin Oncol 2006;24:241-251.

26 Suraweera N, Duval A, Reperant M, et al. Evaluation of tumor microsatellite instability using five quasimonomorphic mononucleotide repeats and pentaplex PCR. Gastroenterology 2002;123:1804-1811.

27 Woerner SM, Benner A, Sutter C, et al. Pathogenesis of DNA repair-deficient cancers: a statistical meta-analysis of putative Real Common Target genes. Oncogene 2003;22:2226-2235.

28 Schwartz Jr S, Yamamoto H, Navarro M, Maestro M, Reventós J, Perucho M. Frameshift mutations at mononucleotide repeats in caspase-5 and other target genes in endometrial and gastrointestinal cancer of the microsatellite mutator phenotype. Cancer Res 1999;59:2995-3002.

29 Ohmiya N, Matsumoto S, Yamamoto H, Baranovskaya S, Malkhosyan SR, Perucho M. Germline and somatic mutations in hMSH6 and hMSH3 in gastrointestinal cancers of the microsatellite mutator phenotype. Gene 2001;272:301-313.

30 Guanti G, Resta N, Simone C, et al. Involvement of PTEN mutations in the genetic pathways of colorectal cancerogenesis. Hum Mol Genet 2000;9:283-287.

31 Piao Z, Fang W, Malkhosyan S, et al. Frequent frameshift mutations of RIZ in sporadic gastrointestinal and endometrial carcinomas with microsatellite instability. Cancer Res 2000;60:4701-4704.

32 Riccio A, Aaltonen LA, Godwin AK, et al. The DNA repair gene MBD4 (MED1) is mutated in human carcinomas with microsatellite instability. Nat Genet 1999;23:266-268.

33 Ripberger E, Linnebacher M, Schwitalle Y, Gebert J, von Knebel Doeberitz M. Identification of an HLAA0201-restricted CTL epitope generated by a tumorspecific frameshift mutation in a coding microsatellite of the OGT gene. J Clin Immunol 2003;23:415-423.

34 Duval A, Gayet J, Zhou XP, Iacopetta B, Thomas G, Hamelin R. Frequent frameshift mutations of the 
TCF-4 gene in colorectal cancers with microsatellite instability. Cancer Res 1999;59:4213-4215.

35 Potocnik U, Glavac D, Ravnik-Glavac M. Identification of novel genes with somatic frameshift mutations within coding mononucleotide repeats in colorectal tumors with high microsatellite instability. Genes Chromosomes Cancer 2003;36:48-56.

36 Souza RF, Appel R, Yin J, et al. Microsatellite instability in the insulin-like growth factor II receptor gene in gastrointestinal tumours. Nat Genet 1996; 14:255-257.

37 Ikenoue T, Togo G, Nagai K, et al. Frameshift mutations at mononucleotide repeats in RAD50 recombinational DNA repair gene in colorectal cancers with microsatellite instability. Jpn J Cancer Res 2001;92:587-591.

38 Huang J, Papadopoulos N, McKinley AJ, et al. APC mutations in colorectal tumors with mismatch repair deficiency. Proc Natl Acad Sci USA 1996;93: 9049-9054.

39 Yamaguchi T, Iijima T, Mori T, et al. Accumulation profile of frameshift mutations during development and progression of colorectal cancer from patients with hereditary nonpolyposis colorectal cancer. Dis Colon Rectum 2006;49:399-406.

40 Fernandez-Peralta AM, Nejda N, Oliart S, Medina V, Azcoita MM, González-Aguilera JJ. Significance of mutations in TGFBR2 and BAX in neoplastic progres- sion and patient outcome in sporadic colorectal tumors with high-frequency microsatellite instability. Cancer Genet Cytogenet 2005;157:18-24

41 Jung B, Smith EJ, Doctolero RT, et al. Influence of target gene mutations on survival, stage and histology in sporadic microsatellite unstable colon cancers. Int J Cancer 2006;118:2509-2513.

42 Samowitz WS, Curtin K, Neuhausen S, Schaffer D, Slattery ML. Prognostic implications of BAX and TGFBRII mutations in colon cancers with microsatellite instability. Genes Chromosomes Cancer 2002; 35:368-371.

43 Tsao JL, Yatabe Y, Salovaara R, et al. Genetic reconstruction of individual colorectal tumor histories. Proc Natl Acad Sci USA 2000;97:1236-1241.

44 Hampel H, Stephens JA, Pukkala E, et al. Cancer risk in hereditary nonpolyposis colorectal cancer syndrome: later age of onset. Gastroenterology 2005;129:415-421.

45 Ogino S, Odze RD, Kawasaki T, et al. Correlation of pathologic features with $\mathrm{CpG}$ island methylator phenotype (CIMP) by quantitative DNA methylation analysis in colorectal carcinoma. Am J Surg Pathol 2006;30:1175-1183.

46 El-Bchiri J, Guilloux A, Dartigues P, et al. Nonsensemediated mRNA decay impacts MSI-driven carcinogenesis and anti-tumor immunity in colorectal cancers. PLoS ONE 2008;3:e2583.

Supplementary Information accompanies the paper on Modern Pathology website (http://www.nature.com/ modpathol) 